\title{
A sífilis e o aggiornamento do organicismo na psiquiatria brasileira: notas a uma lição do doutor Ulysses Vianna
}

\author{
Syphilis and the \\ aggiornamento of \\ organicism in Brazilian \\ psychiatry: notes on a lesson \\ by Dr. Ulysses Vianna
}

CARRARA, Sérgio; CARVALHO, Marcos. A sífilis e o aggiornamento do organicismo na psiquiatria brasileira: notas a uma lição do doutor Ulysses Vianna. História, Ciências, Saúde Manguinhos, Rio de Janeiro, v.17, supl.2, dez. 2010, p.391-399.

\section{Resumo:}

Toma como ponto de partida a lição do psiquiatra brasileiro Ulisses Vianna, publicada em 1919 nos Arquivos Brasileiros de Neuriatria e Psiquiatria, para analisar o modo como se

desenvolviam, naquele momento, as discussões médicas em torno das 'sífilis do sistema nervoso' e 'sífilis cerebral'. Procura inscrever o trabalho de Vianna no horizonte intelectual mais amplo do qual fazia parte e explorar o impacto que essa categoria nosológica teve no pensamento psiquiátrico, especialmente na consolidação de concepções organicistas ou somatológicas a respeito da doença mental, ajustando-as aos novos horizontes inaugurados pela bacteriologia.

Palavras-chave: história da psiquiatria; sistema nervoso; sífilis cerebral; Ulysses Vianna; Brasil.

\section{Abstract}

Taking as its point of departure the lesson published by Brazilian psychiatrist Ulisses Vianna in the Arquivos Brasileiros de Neuriatria e Psiquiatria in 1919, the article analyzes the development of that day's medical discussions about 'syphilis of the nervous system' and 'cerebral syphilis,' situating Vianna's work within its broader intellectual scenario. The article also examines the impact of this disease category on psychiatric thought, especially how it strengthened the organicist or somatological concepts of mental illness and adjusted them to the new scenario created by bacteriology.

Doutorando no Programa de Pós-graduação em Antropologia Social/Museu Nacional/Universidade

Federal do Rio de Janeiro.

Rua Benjamim Constant, 90/202

20241-150 - Rio de Janeiro - RJ - Brasil

dabata@gmail.com

Recebido para publicação em janeiro de 2010. Aprovado para publicação em outubro de 2010.

Keywords: history of psychiatry; nervous system; cerebral syphilis; Ulysses Vianna; Brazil. 
les alienistes qui ne voulaient voir la syphilis nulle part vont des lors la voir partout ...

Quetel, Le mal de Naples.

Em 1919, os Arquivos Brasileiros de Neuriatria e Psiquiatria publicavam a lição intitulada "Sífilis do sistema nervoso", de autoria de um de seus diretores, o doutor Ulisses Vianna. À época, além de médico da Assistência a Alienados do Distrito Federal, Vianna era também docente de Neurologia e Psiquiatria da Faculdade de Medicina do Rio de Janeiro e colaborador de Juliano Moreira, tanto na pesquisa quanto na assistência. ${ }^{1}$ Fora assistente de Alois Alzheimer em Munique e Breslau e voltara ao Brasil com a eclosão da Primeira Grande Guerra.

O objetivo geral da lição de 1919 era fazer um balanço sobre o conhecimento que se tinha então sobre sífilis e sua importância na "produção das doenças nervosas e mentais" (Vianna, 1919, p.164). Continuando uma discussão ocorrida naquele mesmo ano em sessão da Sociedade Brasileira de Neurologia, Psiquiatria e Medicina Legal, a lição refletia o intenso debate internacional que então se desenrolava, a respeito da etiologia somática ou orgânica de um número significativo dessas afecções. ${ }^{2}$ Desse debate participavam eminentes psiquiatras, como Emil Kraepelin, Jean-Martin Charcot e Juliano Moreira, neurologistas como Max Nonne e sifilógrafos como Alfred Fournier - entre aqueles que Vianna fazia questão de invocar logo no início de sua lição.

Neste artigo, procuraremos contextualizar historicamente o trabalho de Vianna e inscrevê-lo no horizonte intelectual mais amplo em que se inseriu. Esperamos, assim, evidenciar o papel estratégico desempenhado pela sífilis do sistema nervoso para o aggiornamento da perspectiva organicista ou fisicalista na reflexão psiquiátrica da primeira metade do século XX.

\section{“Um dos capítulos mais interessantes da neuriatria e da psiquiatria...”}

Para o leitor contemporâneo talvez não seja fácil perceber a importância do tema abordado por Ulysses Vianna nesse texto. Sua linguagem eminentemente técnica, recheada de dados estatísticos, tabelas e gráficos, mal esconde o grande entusiasmo e otimismo que cercavam a matéria. Seguramente, não era à toa que o psiquiatra considerava a sífilis do sistema nervoso "um dos capítulos mais interessantes da neuriatria e da psiquiatria" (Vianna, 1919, p.164). Porém, o interesse dos especialistas pela doença não parecia residir - ao menos naquele momento - na importância estatística dos casos. Os dados apresentados pelo próprio Vianna mostram que sua incidência era quase insignificante. Como contabilizava, de 1905 a 1914 haviam sido diagnosticados 313 casos de 'sífilis cerebral' entre os 11.475 pacientes que passaram pelo Hospício Nacional de Alienados, uma incidência de apenas

N.E. - O presente artigo é uma reflexão crítica baseada em texto de Ulysses Vianna, "Sífilis do sistema nervoso", reproduzido neste número de História, Ciências, Saúde - Manguinhos. 
2,72\%. É verdade que, no intervalo temporal considerado pelo psiquiatra, constatava-se um aumento progressivo nesses números. Mas ele próprio relativizava esse crescimento ao atribuí-lo, ao menos em parte, ao simultâneo desenvolvimento e difusão de técnicas diagnósticas que facilitavam a deteç̧ão de novos casos. Não é, portanto, a importância estatística da doença que permite compreender o interesse que a sífilis do sistema nervoso e mais especificamente a sífilis cerebral despertavam no meio psiquiátrico.

Havia certamente grande inquietação a cercar a sífilis, cujos poderes mórbidos não cessavam de crescer desde o final do século XIX. Já nas primeiras décadas do século seguinte, a doença se transformou definitivamente em espécie de princípio etiológico geral, sendo percebida como causa de um sem-número de quadros sintomáticos. A esse respeito, é reveladora a declaração do sifilógrafo brasileiro Aureliano Werneck Machado (1921, p.177) ao Primeiro Congresso Sul-Americano de Dermatologia e Sifilografia, realizado no Rio de Janeiro em 1918:

Verdadeiro duende da patologia que tem sido a sífilis ininterruptamente desde as suas primeiras explosões, em todos esses quatro séculos, todavia jamais sua importância assumiu a altura da presente época onde ... empolga ainda as atenções gerais como base etiológica que vai se revelando do maior número de entidades nosológicas, mercê dos mais recentes progressos realizados pela ciência experimental (grifos nossos).

E o mais preocupante: a doença podia perpetuar-se através das gerações e, ao corromper o plasma germinativo - como então era denominado o que em algumas décadas viria a ser conhecido como gene -, produzir a degeneração das raças e o declínio das nações. ${ }^{3}$ Como lembrava o próprio Vianna (1919, p.169), "a sífilis se transmite ao homem por contágio direto ou por herança". Vê-se que era ainda bastante forte a crença na existência de uma sífilis propriamente hereditária que, perpetuando-se nas linhagens, podia eclodir em diferentes perturbações físicas, mentais e morais. Para o historiador Alain Corbin (1977), foi principalmente por meio dos trabalhos do sifilógrafo Alfred Fournier e de seu filho, Edmond, que os médicos passaram a atribuir à sífilis "quase todas as más-formações, quase todas as monstruosidades" (p.249). Foi a partir de então que se tornou cientificamente correto dizer que a sífilis era a razão da decadência ou da inferioridade biológica que certas populações exibiam, e combatê-la fazia parte de uma política eugênica mais ampla (Stepan, 1996). ${ }^{4}$

O 'mal venéreo' seria o verdadeiro responsável pela multiplicação desses seres singulares, desviantes, bizarros, perigosos e às vezes geniais que assombravam as elites na passagem do século. Talvez ninguém tenha expressado com maior precisão e elegância o incrível poder que se atribuía à doença como o médico francês Léon Daudet, ele próprio filho de pai 'sifilítico', o escritor Alphonse Daudet:

O micróbio do terrível mal, o treponema, tanto é o aguilhão do gênio e do talento, do heroísmo e da inteligência, quanto da paralisia geral, do tabes e de quase todas as degenerescências. Tanto excitante e estimulante, quanto entorpecedor e paralisante, penetrando e agindo sobre as células da medula e do cérebro, senhor das congestões, das manias, das hemorragias, das grandes descobertas e das escleroses, o treponema hereditário cujo poder aumenta com o cruzamento entre famílias sifilíticas, tem e terá um papel comparável àquele do fatum entre os antigos. Ele é o personagem, invisível, mas presente, que move os românticos desequilibrados, os aberrantes de aspecto sublime, os 
Sérgio Carrara, Marcos Carvalho

revolucionários pedantes ou violentos. Ele é o fermento que faz crescer a massa um tanto pesada do camponês e a refina em duas gerações. Do filho de uma doméstica ele faz um grande poeta e do pacífico pequeno burguês um sátiro, de um marinheiro faz um astrônomo ou um conquistador (citado em Quétel, 1986, p.218).

Como vários historiadores constataram, a passagem do século esteve marcada pela difusão de uma intensa 'sifilofobia', pânico que se perpetuaria até a Segunda Grande Guerra. ${ }^{5}$ Mas, para compreender o interesse que cercava então a sífilis, especificamente a sífilis cerebral, ainda mais importante do que os poderes morbígenos quase infinitos conferidos à doença era o fato de ela ter se tornado então uma espécie de símbolo natural dos poderes da ciência médica, particularmente da ciência médica alemã. Tomando como referência a data de publicação da lição do doutor Vianna, os notáveis 'progressos' médicos que se realizaram em torno da sífilis eram todos bastante recentes. Fazia pouco mais de dez anos que, em 1905, o agente causador da doença - o treponema pallidum - havia sido identificado pelo zoologista Fritz Schaudinn e pelo dermatologista Erich Hoffman, ambos alemães (Souza, 2005). Pouco mais de dez anos havia também que a equipe liderada pelo bacteriologista alemão August von Wassermann desenvolvera, justamente para a sífilis, o primeiro teste sorológico moderno (fixação de complemento), em torno do qual toda uma nova ciência, a imunologia, iria se organizar. ${ }^{6}$

Antes desse teste sorológico, Fernand Widal, Jean A. Sicard e Paul Ravaut já haviam divulgado, em 1901, o exame citológico do líquido cefalorraquidiano, cujo impacto para a psiquiatria Vianna (1919) enfatizava em sua lição. Conforme escreveu, o exame citológico "inaugurou uma época notável de fecundos progressos e inestimáveis consequências no desenvolvimento das doenças nervosas e mentais". A partir dele, como afirma, "muitos doentes que tinham o diagnóstico de psicoses funcionais foram melhor observados e o exame do líquido cefalorraquidiano em vários casos demonstrou que se tratava de uma doença orgânica específica". Para Vianna, com o novo exame, "o domínio das doenças sifilíticas estendeu-se consideravelmente" (p.166).

Além de se aplicar no sangue, o teste de Wasserman também se aplicava no líquido cefalorraquidiano e assim comprovava que o sistema nervoso havia sido atingido pelo mal. Ulysses Vianna conhecia intimamente o teste de Wasserman, pois com o bacteriologista Arthur Moses, então assistente do Instituto Oswaldo Cruz, havia desenvolvido pesquisa sobre a quantidade necessária de líquido cefalorraquidiano para que se produzissem resultados confiáveis. ${ }^{7}$ Em sua lição, Vianna (1919, p.166) não deixava de sublinhar a importância do novo método diagnóstico para a psiquiatria e a neurologia: "A reação de desvio de complemento empregada por Wassermann, Neisser e Bruck solidificou o edifício da sífilis mental".

A esse respeito, como afirma a historiadora Ilana Löwy (1993, p.86-87), "um teste positivo era considerado - particularmente no período inicial de entusiasmo pelo novo método não como algo que pudesse auxiliar o diagnóstico, mas como uma prova infalível de infecção treponêmica". Apenas depois da Segunda Guerra, ao surgirem testes que possibilitaram detectar o próprio treponema na corrente sanguínea, e não apenas os anticorpos supostamente produzidos para combatê-lo, verificou-se que milhares de pessoas teriam sido erroneamente diagnosticadas como portadoras de sífilis, pois a reação resultava 
positiva para muitos outros males. Para certas populações, diz Löwy, o número de falsos positivos podia ser assombroso.

Enfim, coroando esse processo, fazia exatos dez anos que, em 1909, se divulgara a descoberta de um quimioterápico considerado específico para a sífilis. Tratava-se de uma droga sintética, a primeira do gênero. Derivada de sais de arsênico, foi batizada de Salvarsan, sendo popularmente conhecida como 606. A nova maravilha científica foi desenvolvida também na Alemanha por uma equipe de pesquisadores liderada por Paul Ehrlich, que se referia à nova droga como uma 'bala mágica' porque, uma vez dentro do organismo, iria supostamente localizar e eliminar apenas os treponemas.

\section{O impacto da sífilis na medicina mental}

Na psiquiatria, a sífilis oferecia, sobretudo, uma nova inteligibilidade para as demências, especialmente para a 'paralisia geral progressiva' ou 'demência paralítica' ${ }^{8}$ Desde o final do século XIX, o sifilógrafo francês Alfred Fournier, sem dúvida o mais consagrado especialista da época, havia defendido, como bem lembrava Vianna (1919, p.165), a origem sifilítica da paralisia geral progressiva. Essa hipótese, que também merecia o crédito de Kraepelin, se transformaria em certeza em 1913, quando, apenas seis anos antes de a lição de Vianna ser publicada, Hydeo Noguchi e Joseph W. Moore (1913), do Instituto Rockefeller Para Pesquisas Médicas, anunciaram a descoberta do treponema pálido no cérebro de pacientes acometidos pela doença.

Não deixa de ser surpreendente o modo pelo qual uma entidade nosológica particular - a paralisia geral progressiva - foi estratégica para a afirmação do organicismo no campo dos 'problemas mentais'. Em dois momentos históricos, separados por quase um século, ela desempenhou papel crucial na integração, tão desejada por psiquiatras e alienistas, de sua disciplina aos paradigmas mais legítimos da ciência médica. A doença, que já no início do século XIX havia sido apresentada por Laurent-Antoine Bayle como a prova indiscutível de que a alienação mental era fruto de lesões cerebrais, era agora transformada, quase um século depois, em uma das mais graves manifestações da sífilis do sistema nervoso. Serviu a partir daí de emblema para a ideia de que a doença mental não só tinha causas orgânicas, mas que tais causas habitavam o fantástico universo dos infinitamente pequenos. Estendia-se, assim, uma ponte entre psiquiatria e bacteriologia, entre clínica e laboratório, franqueando à loucura a entrada na 'era microbiana'.

Além da paralisia geral progressiva, ao redor da sífilis e da degeneração do sistema nervoso por ela provocada começavam também a orbitar tabes dorsalis, epilepsia, histeria, melancolia, mania, depressão, paranoia e outras figuras da loucura, que passavam a ser consideradas apenas como quadros sintomáticos. A partir do sistema nervoso, a sífilis se tornava uma 'doença total' e começava a ser apontada até mesmo como causa de comportamentos imorais e atos delituosos. Diante disso, não deve causar espanto o adágio cunhado pelo doutor Antônio Austregésilo - primeiro ocupante da cátedra de Neurologia da Faculdade de Medicina do Rio de Janeiro, criada em 1912 -, que seria repetido ad nauseam durante todo o século XX: "em clínica, deve-se pensar sifiliticamente". ${ }^{9}$ 
Sérgio Carrara, Marcos Carvalho

No final de sua lição, Vianna apresenta uma proposta de classificação do que denomina cerebrossifilose adquirida ou hereditária. Nela, articula observações clínicas e anatomopatológicas em um sistema exemplar para todas as outras afecções nervosas e mentais. Dependendo da localização da lesão produzida no cérebro pelo treponema, se nas artérias ou meninges, e sua forma, se gomosa ou não, a sífilis cerebral podia produzir um grande número de sintomas físicos, como cefaleias, entorpecimentos, apoplexias, vertigens, hemiplegias, afasias, convulsões. Mas também sintomas que Vianna ora designa como mentais, ora como intelectuais: depressão, esquecimentos, alucinações, delírios (especialmente os de grandeza). É importante lembrar que vários desses sintomas, ou sua combinação, eram ainda considerados, à época, entidades nosológicas específicas por muitos alienistas. A classificação proposta por Vianna ultrapassava claramente o nível dos sintomas para se ater ao nível das lesões e de suas causas.

Apesar da 'modernidade' da lição de Vianna, não podemos deixar de notar que alguns temas caros ao alienismo nela permanecem. Assim, por exemplo, mesmo que na estatística compilada pelo autor os operários figurassem como a maioria entre os atingidos pelo mal, o "trabalho intelectual em excesso", com o alcoolismo e o "traumatismo", continuava presente como causa predisponente da sífilis cerebral. O exercício muito intenso das funções cerebrais, antes considerado causa eficiente da demência, aparecia agora como sua causa predisponente.

\section{Conclusão: a sífilis cerebral e o aggiornamento do organicismo}

A 'modernidade' que a sífilis cerebral imprimia à psiquiatria da primeira metade do século XX parece ter contribuído decisivamente para o aggiornamento da perspectiva organicista ou somatológica. Talvez devamos mesmo considerar a demência paralítica, agora compreendida como sífilis cerebral, como a primeira 'doença mental' para cujo tratamento foi desenvolvido um quimioterápico considerado eficaz. Nesse sentido, sob a égide das teorias de Kraepelin, que tanto influenciavam a psiquiatria brasileira daquele momento $^{10}$, a sífilis do sistema nervoso temperava o pessimismo terapêutico que teria sido característico da psiquiatria organicista até então (Shorter, 1997).

Os psiquiatras alemães haviam se mostrado confiantes no 'desvelamento' das causas das doenças mentais e céticos no que se refere ao tratamento e à probabilidade de cura, tendendo assim a separar clínica e pesquisa experimental. Diante disso, a reflexão em torno da sífilis cerebral permitia-lhes, e principalmente aos especialistas brasileiros, cuja tradição vinculava muito mais fortemente ciência e assistência (Venâncio, 2003), superar tal impasse. Isso se evidencia com clareza já na publicação do primeiro número dos Archivos, no qual, no já mencionado artigo sobre a reação de Wassermann, Ulysses Vianna e Arthur Moses (1919, p.5) afirmavam:

Restaurar os cordões nervosos degenerados é utopia, mas tratar a meningite que precede a degeneração e assim evitá-la não só não é utopia, como é observação de especialista. Assim procedendo, curar-se-iam casos incipientes de sífilis cerebroespinhal, melhorar-seiam outros de tabes e estabelecer-se-iam mais largas remissões nos de paralisia geral. A leitura das observações que se seguem, coligidas e estudadas clinicamente pelo primeiro 
[Vianna] e no laboratório pelo segundo [Moses], revelará à sociedade que muitos passam pelos manicômios com o rótulo de psicose tóxica ou toxi-infecciosa, demência precoce, alcoolismo, tendo, no entanto, sintomas estritamente ligados à sífilis.

A importância da sífilis cerebral para a perpetuação da perspectiva organicista em psiquiatria até meados do século XX foi claramente percebida pelo psiquiatra Heitor Pereira Carrilho (1941), que, à época da publicação da lição de Ulysses Vianna, era o encarregado de compilar as atas das reuniões da Sociedade Brasileira de Neurologia, Psiquiatria e Medicina Legal. Como escreve ele no início dos anos 1940, já então como a grande autoridade brasileira em psiquiatria forense, o fato de muitos atos delinquentes terem sua origem na perturbação do sistema nervoso produzida pela sífilis acabava por "revelar o acerto dos que ... sustentavam que toda ação é organicamente determinada" (p.169).

A importância estratégica da sífilis para a psiquiatria logo traria reflexos institucionais. Quando, em 1919, o professor Ulysses Vianna publicou sua lição sobre a sífilis do sistema nervoso, seguramente não imaginava que o serviço em que trabalhava na Assistência a Alienados do Rio de Janeiro iria se transformar, em 1937, no Instituto de Neurossífilis, e muito menos que tal instituto sobreviveria até nossos dias como Instituto Philippe Pinel. ${ }^{11}$ E, afinal, não deixa de ser irônico que um instituto construído sobre uma das mais bem acabadas peças da psiquiatria organicista alemã tenha chegado até nós com o nome do alienista francês que tão firmemente sustentava que a loucura tinha causas morais.

A partir de 1970, sobretudo durante os anos 1990, nota-se um significativo crescimento do número de casos de neurossífilis, agora associados à infecção do vírus da imunodeficiência humana (HIV-AIDS) (Barros et al., 2005). É também curioso que a sífilis venha retomando algo de sua antiga importância justamente por meio de sua nova articulação com a AIDS - uma síndrome que, desde seu surgimento, é também marcada pelo estigma da impureza moral, da sexualidade desviante e até mesmo do pecado.

\section{NOTAS}

${ }^{1}$ Em 1916, no Primeiro Congresso Brasileiro de Neurologia, Psiquiatria e Medicina Legal, Ulisses Vianna e Juliano Moreira haviam apresentado, em coautoria, trabalho sobre tema vinculado à sífilis do sistema nervoso: "Contribuição ao estudo da demência paralítica no Rio de Janeiro" (Vianna, 1919, p.170). Ambos, com Arthur Moses, seriam condecorados com a medalha de ouro da Universidade de Hamburgo, em 1926. Em 1930, Vianna publicou uma separata sobre o 'mestre' intitulada "Professor dr. Juliano Moreira", na prestigiosa Zeitschrift fur die gesamte Neurologie und Psychiatrie (Vianna, 1930). Em 1921, com Adauto Botelho, Pedro Pernambuco e Antônio Austregésilo, fundou o Sanatório Botafogo, que durante os anos 1920 manteria o Pavilhão Juliano Moreira para alienados, "especialmente construído de acordo com os planos da Clínica de Munich dirigida pelo prof. Emillio Kraepelin”, conforme propaganda veiculada na contracapa de diferentes números dos Arquivos Brasileiros de Neuriatria e Psiquiatria.

${ }^{2} \mathrm{O}$ debate colocava em causa o próprio estatuto do 'mental', que no trabalho de Vianna é usado como sinônimo de 'intelectual' e está explicitamente vinculado ao plano sintomatológico, no qual as afecções do sistema nervoso podiam assumir múltiplas formas. Uma discussão detalhada sobre as complexas relações e mediações entre o mental, o psicológico, o nervoso e o moral no pensamento psiquiátrico encontra-se no trabalho pioneiro de Duarte (1986).

${ }^{3}$ Para uma discussão sobre as teorias da degeneração e seu impacto na psiquiatria, ver, entre outros Nye, 1984; Pick, 1989; Somont de Serpa, 1998; e Carrara, 1997.

${ }^{4}$ Cabe lembrar que, para Stepan (1996), a crença no caráter hereditário da sífilis contribuiu significativamente para que, em países como o Brasil, teorias neolamarckianas merecessem crédito até meados do século XX, fazendo com que 'sanear' pudesse ser considerado sinônimo de 'eugenizar'. 
${ }^{5}$ Sobre o tema ver, entre outros, Corbin, 1988; Quetel, 1986; Brandt, 1985; e Carrara, 1996.

${ }^{6}$ Sobre o tema, ver o clássico trabalho de L. Fleck (1979).

7 Os resultados desse trabalho foram publicados no primeiro número dos Arquivos, sob o título "Diagnóstico das afecções nervosas e mentais pelo emprego de elevadas quantidades de líquido cefalorraquiano" (Vianna, Moses, 1919). Para seus autores, o novo procedimento autorizava a distinguir entre a forma esquizofrênica da sífilis cerebral e a demência precoce.

${ }^{8}$ Em célebre tratado sobre a demência precoce, embora cético, Kraepelin (1919) deixava ainda aberta a possibilidade de a sífilis hereditária ser uma de suas causas.

9 O adágio aparece citado pelo próprio Austregésilo, no Boletim da Sociedade Brasileira de Neurologia, Psiquiatria e Medicina Legal, que divulgou a ata da sessão ordinária realizada em junho de 1919, em que se discutiram casos clínicos de 'heredossífilis' apresentados por Vianna (Arquivos Brasileiros de Neuriatria e Pssquiatria, 1919, 3o trim., p.293). O sucesso do adágio foi tão grande que ainda atualmente pode ser encontrado em vários artigos e outros trabalhos médicos.

${ }^{10}$ Com a teoria kraepeliana, como esclarece Venâncio (2003, p.890), "passava-se a privilegiar e consolidar o interesse pelas relações causais entre distúrbios somáticos e consequências mentais, procurando sistematizar as entidades mórbidas mentais, a exemplo das orgânicas, para efeito das classificações nosográficas. Era uma retomada da psiquiatria pela própria psiquiatria, viabilizada pela esperança nas pesquisas na área da anatomia patológica que respaldava o modelo da observação clínica".

${ }^{11}$ Quando, no decorrer da década 1940, a sífilis perdeu consideravelmente sua importância sanitária e simbólica, em parte devido à crença de que o advento da penicilina havia finalmente tornado a doença um mal menor, um instituto voltado à neurossífilis parece ter se tornado anacrônico.

\section{REFERÊNCIAS}

BARROS, Ana M. et al.

Neurossífilis: revisão clínica e laboratorial.

Arquivos de Medicina, Porto, v.19, n.3, p.121-129. 2005.

BRANDT, Allan M.

No magic bullet: a social history of venereal disease in the United States since 1880. New York: Oxford University Press. 1985.

CARRARA, Sérgio.

Crime e loucura: o aparecimento do manicômio judiciário na passagem do século. Rio de Janeiro: EdUerj. 1997.

CARRARA, Sérgio.

Tributo a Vênus: a luta contra a sífilis no Brasil da passagem do século aos anos 40.

Rio de Janeiro: Fiocruz. 1996.

CARRILHO, Heitor P.

Neuro-sífilis e delinqüência. In: Conferência Nacional de Defesa contra a Sífilis, 1. Anais.. Rio de Janeiro: Imprensa Nacional. 1941.

CORBIN, Alain.

La grande peur de la syphilis. In: Bardet, Jean-Pierre et al. (Org.). Puers et terreurs face à la contagion: choléra, tuberculose et syphilis -

XIXe. et XXe. siècles. Paris: Fayard. p.333-334. 1988.

CORBIN, Alain.

Le péril vénérien au debut du siècle: prophylaxie sanitaire et prophylaxie moral. Recherches, Paris, v.11, n. 29, p.245-283. 1977.

DOMONT DE SERPA, Octavio.

Mal-estar na natureza. Belo Horizonte: Te Corá. 1998.

DUARTE, Luiz Fernando D.

Da vida nervosa nas classes trabalhadoras urbanas. Rio de Janeiro: Jorge Zahar. 1986.

FLEK, Ludwik.

Genesis and development of a scientific fact.

Chicago: The University of Chicago Press. 1979.

KRAEPELIN, Emil.

Dementia proecox and paraphrenia. Edimburgo:

G.M. Robertson. 1919.

LÖWY, Ilana.

Testing for a sexually transmissible disease, 1907-1970: the history of the Wasserman reaction. In: Berridge, Virginia; Strong, Philip (Ed.). AIDS and contemporary history.

Cambridge: Cambridge University Press. p.74-92. 1993.

MACHADO, Aureliano Werneck.

Contribuição para o estudo da sífilis no Rio de Janeiro. $2^{o}$ Boletim do VIII Congresso Brasileiro de Medicina e do 1o Congresso Sul-Americano de Dermatologia e Sifilografia, Rio de Janeiro. 1921. 
NOGUCHI, Hideyo; MOORE, Joseph W. A demonstration of treponema pallidum in the brain in cases of general paralysis. The Journal of Experimental Medicine, New York, v.17, p.232-238. 1913.

NYE, Robert A.

Crime, madness \& politics in modern France: the medical concept of national decline. Princeton: Princeton University Press. 1984.

PICK, Daniel.

Faces of degeneration: an European disorder. Cambridge: Cambridge University Press. 1989.

QUÉTEL, Claude.

Le mal de Naples: histoire de la syphilis. Paris: Seghers. 1986.

SHORTER, Edward.

The history of psychiatry: from the era of the asylum to the age of prosac. New York: John Wiley \& Sons. 1997.

SOUZA, Elemir M.

Há 100 anos a descoberta do treponema pallidum. Anais Brasileiros de Dermatologia, Rio de Janeiro, v.80, n.5, p.574-8. 2005.
STEPAN, Nancy L.

'The hour of eugenics': race, gender and nation in Latin America. Ithaca: Cornell University Press. 1996.

VENÂNCIO, Ana Teresa A.

Ciência psiquiátrica e política assistencial: a criação do Instituto de Psiquiatria da Universidade do Brasil. História, Ciências, Saúde - Manguinhos, Rio de Janeiro, v.10, n.3, p.883-900. 2003.

VIANNA, Ulysses. Professor Dr. Juliano Moreira. Zeitschrift für die gesamte Neurologie und Psychiatrie, Berlin, v.149, n.1-3, p.429-432. 1930.

VIANNA, Ulysses.

Sífilis do sistema nervoso. Archivos Brasileiros de Neuriatria e Psychiatria, Rio de Janeiro, p.164-176. 1919.

VIANNA, Ulysses; MOSES, Arthur.

Diagnóstico das affecções nervosas e mentaes pelo emprego de elevadas quantidades de liquido cephalo-rachiano. Archivos Brasileiros de Neuriatria e Psychiatria, Rio de Janeiro, v.1, p.1-49. 1919. 